\title{
Vulnerability Analysis of Land Instability Using Multi-Criteria Evaluation for Urban Sustainability: Methodological Overview and Case Study Assessment
}

\author{
Ali Amasha \\ Remote Sensing, GIS \& Natural Hazards Assessment, Arab Academy for Science, Technology and Maritime Transport \\ (AASTMT), Cairo, Egypt \\ Email: aliamasha@gmail.com, ali.amasha@aast.edu
}

How to cite this paper: Amasha, A (2018). Vulnerability Analysis of Land Instability Using Multi-Criteria Evaluation for Urban Sustainability: Methodological Overview and Case Study Assessment. Journal of Geoscience and Environment Protection, 6, 124-138.

https://doi.org/10.4236/gep.2018.611010

Received: September 7, 2018

Accepted: November 23, 2018

Published: November 26, 2018

Copyright $\odot 2018$ by author and Scientific Research Publishing Inc. This work is licensed under the Creative Commons Attribution International License (CC BY 4.0).

http://creativecommons.org/licenses/by/4.0/

\begin{abstract}
There were many developed urban areas have been established without well studied from the hazards perspective. However, Mokattam Plateau is one of the most vulnerable areas of frequent landslides and rock-falls disasters (Moustafa et al., 1991). So, an integrated analysis method is highly needed. Spatial analysis of Multi-criteria evaluation (MCE) provided an assessment of the hazards' factors (i.e. faults, joints, lithology, slope, old wadies/surface drainage, and quarries) at Mokattam area. The data have been analyzed by the MCE, Analytical Hierarchy Process (AHP)/Ordered Weighted Average (OWA)/Weighted Linear Combination (WLC). The research found that the geological factors (faults, joints, and lithology) were the highest contributors by about $65 \%$ of the hazardous driving forces, while the geomorphological processes (slope and old wadies/surface drainage) were contributed by about $30 \%$. In addition, the impact of the human activities such as random urbanization, excess use of irrigation water and the transportation are critical hidden drivers that affect the land instability and accelerates the landslides and rock-falls (Amasha, 2009). Therefore, the decision makers and urban planners have to consider the four scenarios of low risk-high tradeoff (MIDAND), and high risk-some tradeoff (MIDOR) in their disaster risk management plans. While the risk-taking (OR) option is highly recommended for the new urban development projects to ensure the sustainability and risk resilience. While the risk-averse (AND) scenario is not recommended.
\end{abstract}

\section{Keywords}

Hazards Assessment, Driving Forces, Land Instability, MCE-AHP-OWA, 
Resilience, Spatial Analysis

\section{Introduction}

Egypt has rapid population growth that reached 92.1 Million inhabitants (inside the country) in 2017 and 90.1 in 2016 compared with 71.3 in 2006 by increase rate about $20 \%$ through 10 years (CAPMAS, 2017). Such overpopulation growth requires more residential housing and urban development to accommodate population. The Egyptian government has encouraged the urban development projects outside the Nile Delta and flood plain to rescue the fertile land for agriculture and food security. According to this governmental plan, there are many new cities have been developed over the last two decades for residential and industrial purposes.

In the case of Greater Cairo, most of the urban expansion was normally slummy adjacent to the old urbanized areas. It is however, expanded to the desert with more modern urban planning. The critical issue is that, most of these new cities and urbanization have not thoroughly investigated in respect of determining the land stability and geo-environmental hazards. Unfortunately, there is potential disaster, related to the bedrock instability and compliance with urbanization in addition to flood hazard in other areas. Therefore, there is an urgent need to evaluate these areas before any development in order to reduce the number and the frequency of hazards and to mitigate their risk.

The GIS modeling is a potential approach for multiple analyses to estimate different scenarios of site hazard/suitability. Such approach enables decision makers to obtain alternative developmental strategies to be examined and compared before making approval of the implementation plans (Albrecht, 1996). GIS has been widely used in assessing geologic hazards, site selection, and geo-environmental evaluation (Lee \& Pradhan, 2006; Lee \& Pradhan, 2007; Pradhan \& Lee, 2007). The GIS techniques and statistical models are used in evaluating landslide hazards (Carrara et al., 1991), in addition to risk analysis (Pradhan et al., 2009; Pradhan \& Lee, 2009a, 2009b; Carver, 1991), integrated multi-criteria evaluation and GIS with geological information. It had been developed a method to combine mapping and engineering properties using a GIS to evaluate natural hazards (Gunawan et al., 1992).

The AHP is a multi-criteria decision-making approach introduced by (Saaty, 1977), in which a series of pair-wise comparisons between factors have developed to create a scaled set of preferences. It also well documented in (Saaty, 1996) and (Saaty, 2003) literatures. The added-value of this multi-criteria model is considering the weights and cross correlation of each factor relative to every other factor.

It is quite difficult to define precisely MCE Analysis. However, various definitions appear in literature. One common definition is that of (Roy, 1996), who 
postulated that MCE is a decision-aid and a mathematical tool allowing the comparison of different alternatives or scenarios according to many criteria, often contradictory, in order to guide the decision maker(s) towards a judicious choice.

Therefore, this research explore the potentiality of using MCE-AHP to spatially analyze the natural hazards factors at Mokatam Plateau Area and provide informed decisions to support planning and preventing/mitigating socio-economic disaster risks.

\section{Area of Study}

The area of study-Mokatam Plateau Area (MPA) is located eastern of the Cairo built up area, Figure 1. It characterizes by the informal urbanization over and down the plateau where it recorded the highest population density in Cairo, more than 25,000 inhabitants in the sq. km (Amasha, 2009). It is considered as one of the most vulnerable areas for natural hazards with major impact on socio-economy of the population. This includes frequent landslides, rock falls and swelling of the hydrated clayey beds. There were two massive rock-falls reported in 1993 and 2008 that have been caused human deaths, with losses in the urban and public utilities at the foot of the north western cliff of the MPA, Figure 2. In addition, there are many buildings have damaged due to the continuous differential subsidence at the top of the plateau (NARSS \& EGSMA).

\section{Vulnerability of the Area of Study to Natural Hazards}

Mohatam plateau area (MPA) is considered a common vulnerable area for landslides and natural hazards. Few critical factors are driving its sensitivity to natural hazards, such as atmospheric conditions that critically play a key role in the exogenic driving force (Amasha, 2009). The system in equilibrium can be defined by real parameters that represent the limits of the balance condition, whereas the limits of equilibrium have critical conditions called thresholds. The threshold conditions develop in response to gradual changes within the system. In many cases, threshold represents a deterioration of resistance rather than an increase in the driving forces (Schumm, 1973; Ritter, 1988).

Regarding to the lithological aspects, there are five claystone beds, 5 to 10 meters thickness, existing between Upper Eocene Ain Musa Bed and Middle Eocene limestones inter-bedded with marl. The claystone, especially the uppermost beds, are characterized by flow structures. This claystone beds has the highest swelling potential due to the occurrence of montmorillonite clay mineral (Moustafa et al., 1991).

Structurally, the Middle and Upper Eocene foundation bedrocks of MPA are dissected by several joint sets that classified into four sets. Two of these sets are predominant, conjugate and oriented WNW-NW. They have dip angles ranging between $65^{\circ}$ and $90^{\circ}$. The Middle Eocene rocks of Middle Plateau have inclined joints $45^{\circ}-65^{\circ}$ (Moustafa et al., 1991). 


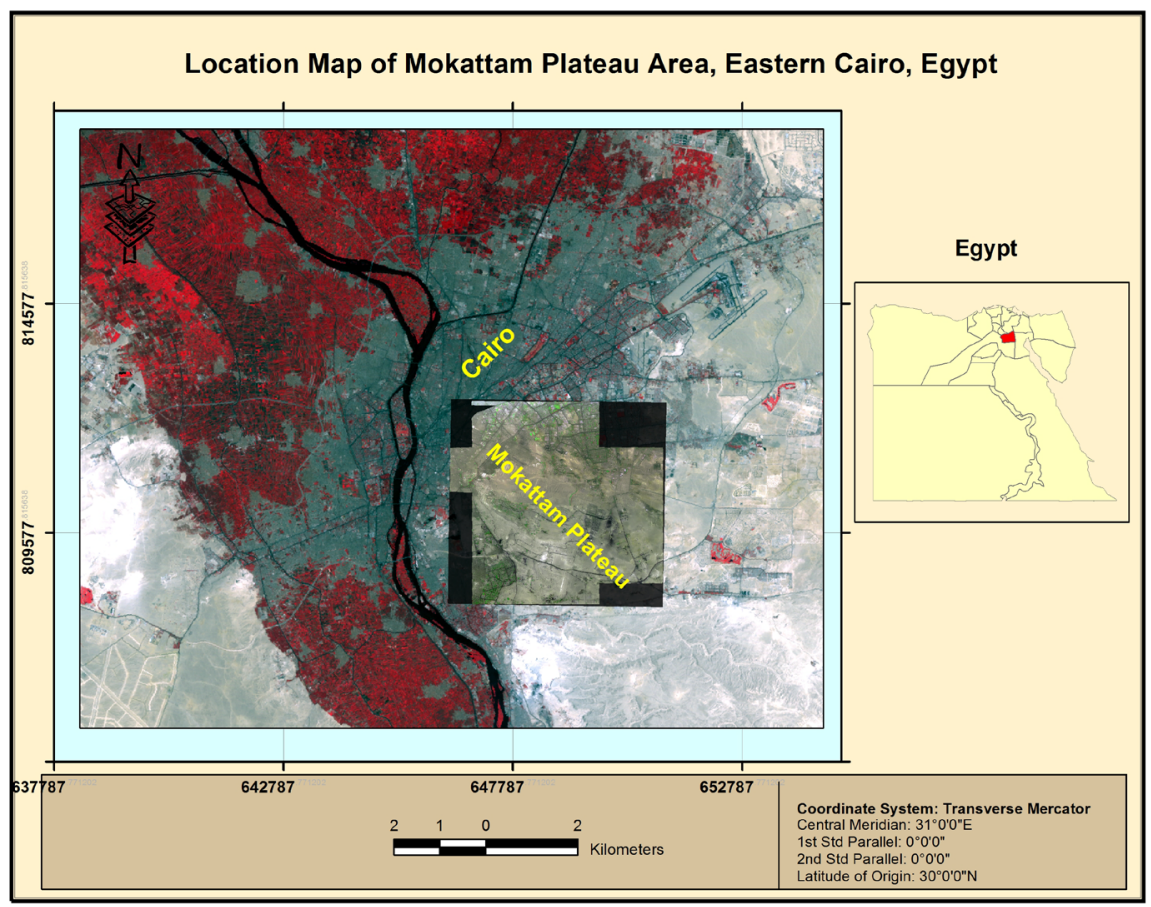

Figure 1. Location map of the Mokattam Plateau study area.

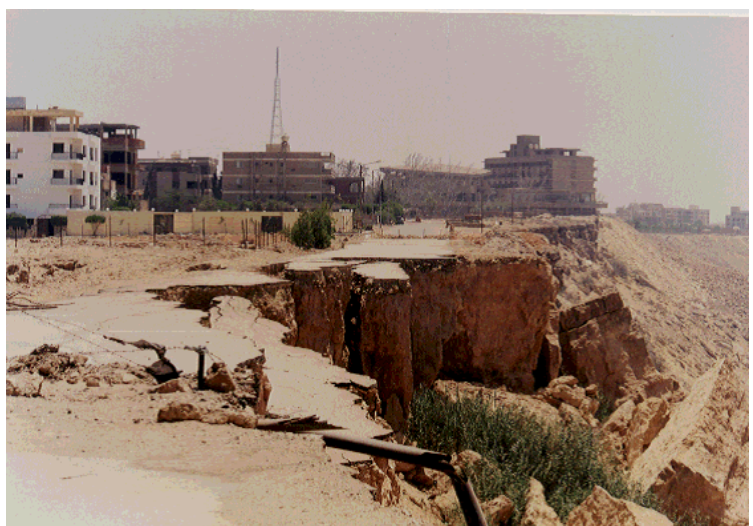

(a)

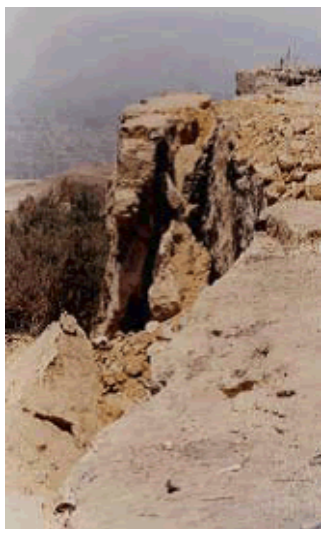

(b)

Figure 2. (a) Urban communities close to the steep cliffs of the Southern Upper Plateau; (b) rock cracks and failure along the cliff.

Topographically, the relative high cliffs of the studied area (223 $\mathrm{m}$ a.m.s.l.), the slope stability plays a key factor that controlling the mass movements and slope failure. It is evaluated based on the other factors of lithology, geologic structure, differential physical weathering and the topography. Slope stability, therefore, represents some balance between driving forces (shear stresses) and resisting forces (shear strength), this can be expressed as a safety ratio (Ritter et al., 2001):

$$
\mathrm{F}=\frac{\text { Resisting Force }(\text { Shear StrFength })}{\text { Driving Force }(\text { Shear Stress })}
$$


Theoretically, failure occurs when $\mathrm{F}=1$.

Beside the natural driving forces affecting the high potential risk on MPA, the impact of human activities, is an important factor which accelerates the land instability. The human activities include the urbanization on the highly-potential risk foundation bed rocks, especially of Upper Eocene rocks of the Upper Plateau. The leakage of sewage water, the irrigation of the urban green areas and the limestone quarrying pumps are considered as important factors in the land instability of the Mokattam Plateau area (Amasha, 2009).

\section{Materials and Methodology}

To apply the GIS modelling and analysis, an initial step was to prepare geographic layers. Six GIS layers that represent hazards factors were prepared and classified into four sub-groups as follows:

1) Structural Geology (Faults \& joints),

2) Stratigraphy (lithology),

3) Geomorphology (slope as topography and old wad is/surface drainage)

4) Human activities (old quarries) in addition to the urbanization settlements.

ArcGIS Desktop package was used for spatial and layer preparation, IDRISI package was used for MCE Model and make statistical and mapping analysis via the following steps:

- GIS functions were applied to create distance layers of faults, joints, drainage, slope and lithology. This followed by creating proximity layers for faults, joints, surface drainage (wadies) and quarries.

- Weighting scale was applied to lithology layer from 1 - 9 scale according to the effect on hazards. However, slope was scaled as gradient in degrees. Therefore, the vulnerability of slope as a hazard factor is clearly observed at the boundaries of the Plateaux where cliffs occur.

- All layers were aggregated to 0 - 255 scaled before MCE analyses.

- Define the hazard assessment as single objective for the MCE model; this was functioned by overlaying of several thematic layers to identify zones that are common to given criteria. Furthermore sieve mapping is used to examine all layers to identify zones that encompass all desired criteria (Eastman, 2006).

To meet a specific objective, it is frequently the case that several criteria will need to be evaluated. Such a procedure is called Multi-Criteria Evaluation (Voogd, 1983; Carver, 1991).

Due to the existence of different scales of the criteria that might create uncertainty, it is necessary that all criteria factors are standardized before combination. A review of variety of procedures for standardization typically had been used the minimum and maximum values as scaling points (Carver, 1991). The simplest approach that adopted is a linear scaling (Equation (2)):

$$
X i=\frac{\left(R i-R_{\min }\right)}{\left(R_{\max }-R_{\min }\right) * s \text { tan dardized_range }}
$$


where $R=$ raw score.

In IDRISI, the FUZZY module is provided for the standardization of factors using a whole range of fuzzy set membership functions (Eastman \& Jiang, 1996). The module provides the option of standardizing factors to either a 0 - 1 real number scale or a 0 - 255 byte scale. This latter option is recommended because the MCE module has been optimized for speed using a 0 - 255 level standardization. Importantly, the higher value of the standardized scale must represent the case of being more likely to belong to the decision set.

The implementation of this standardization approach, for the used criteria, aggregations were as the following processes:

- Fault-distance layer is processed as Sigmoidal function type and Monotonically decreasing function shape;

- Joints-distance layer is processed as Sigmoidal function type and Monotonically decreasing function shape;

- Lithology-distance layer is processed as Sigmoidal function type and Monotonically decreasing function shape;

- Slope-distance layer is processed as J-shaped function type and Monotonically increasing function shape;

- Wadies-distance layer is processed as J-shaped function type and Monotonically decreasing function shape;

- Quarries-distance layer is processed as Linear function type and Monotonically decreasing function shape;

- The AHP pair-wise comparison matrix between the standardized 6 factors is edited to produce Eigen vector values. These Eigen values considered as weights of factors.

Finally, based on the pair-wise comparison matrix that had developed by (Saaty, 1980), an estimated weight is calculated to derive a consistency ratio (CR) to produce eigenvector values in terms of weights. The calculated weights of the applied factors in our work are: Faults 0.0914, Joints 0.2227, Lithology 0.3343, Slope 0.1741, Wadies 0.1234 and Quarries 0.0541. The (CR) in our work is calculated as 0.08 which is less than 0.10 as recommended. So, it is accepted.

The Simple Additive Weighting (SAW) or Weighted Linear Combination (WLC) is the most often used technique in multi-criteria decision making. Criteria here may include weighted factors and constraints. Calculating the product of weight and factor multiplied with all constraints at any location, and then summing up all products yields a total overall score. The score for each alternative A is shown as in Equation (3) (Eastman, 2006):

$$
A=S U M(w i * x i) \rightarrow O R \rightarrow A=S U M(w i * x i) * S U M(c j)
$$

If a constraint is part of the decision,

$w i=$ weight of factor $i$,

$x i=$ criterion score of factor $i$,

$c j=$ criterion score of constraint $j$. 
The OWA may also be incorporated into the criteria aggregation process. The order weights are applied pixel by pixel to the order of suitability scores. The effect of order weights is most easily understood in terms of levels of risk and tradeoff (Yager, 1988). Factor Weights; Specify weights for factors to produce an output of a decision map using the user-defined weights by applying the pair-wise comparison matrix (Saaty, 1977). This has finally created decision maps using the AHP weights and the ordered weighted averaging (OWA), Table 1 and Figure 3.

With a weighted linear combination (WLC), factors are combined by applying a weight to each, followed by summation of the results to yield a suitability map (Voogd, 1983), i.e.:

$$
S=\sum w i x i
$$

where $S$ = suitability,

$w i=$ weight of factor $i$,

$x i=$ criterion score of factor $i$.

Table 1. The selected four AHP-OWA scenarios' models' weights and orders.

\begin{tabular}{ccccccc}
\hline & \multicolumn{7}{c}{ Order } \\
\hline Models' weights & 1 & 2 & 3 & 4 & 5 & 6 \\
Risk-averse (AND) & 1 & 0 & 0 & 0 & 0 & 0 \\
Low risk-high tradeoff (MIDAND) & 0.5 & 0.2 & 0.15 & 0.1 & 0.05 & 0 \\
High risk-low tradeoff (MIDOR) & 0 & 0.05 & 0.1 & 0.15 & 0.2 & 0.5 \\
Risk-taking (OR) & 0 & 0 & 0 & 0 & 0 & 1 \\
\hline
\end{tabular}

MCE AHP-OWA Scenarios

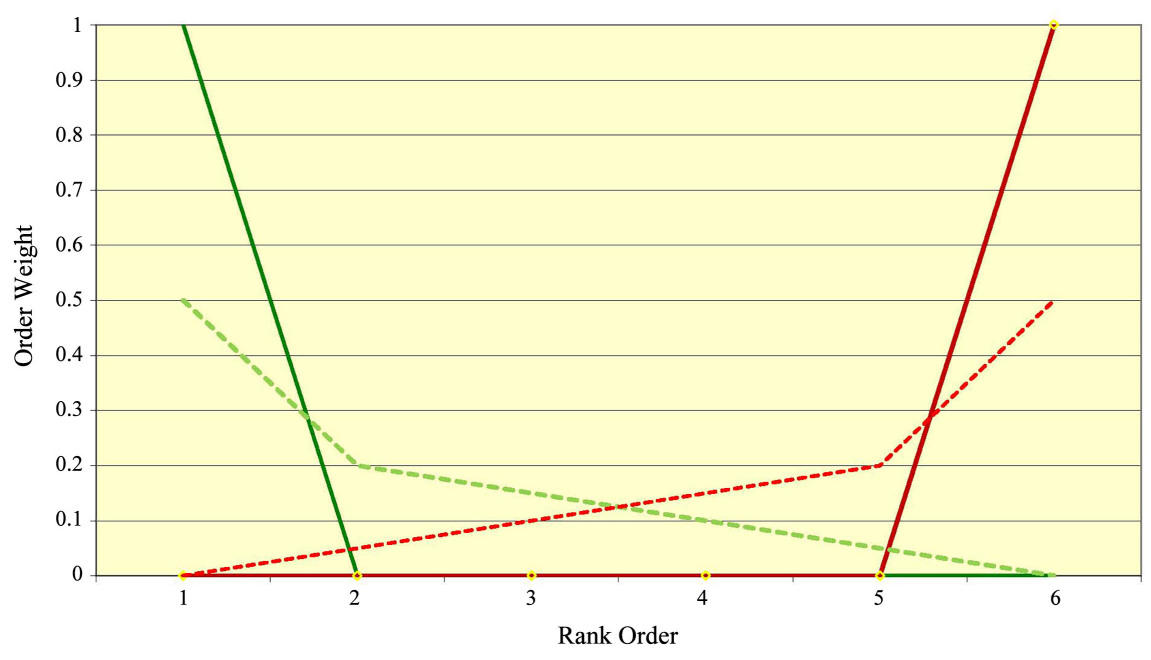

—Weight (AND) - - -Weight (OR) $\quad---$ Weight (MIDAND) $\quad----$ Weight (MIDOR)

Figure 3. Plotting the four AHP-OWA scenarios' weights and order. 
In cases where Boolean constraints also apply; the procedure can be modified by multiplying the suitability calculated from the factors by the product of the constraints (Voogd, 1983), i.e.:

$$
S=\sum w i x i * \Pi c j
$$

where $c j=$ criterion score of constraint $j$,

$$
\Pi=\text { product. }
$$

\section{Results and Discussion}

\section{MCE and Ordered Weighted Average (OWA)}

The outcomes of the MCE are categorized into different scenarios according to the options have been taken between the risk and trade off. The order weights that generated these decision maps are scaled from (risk-averse, minimum, AND) to (risk-taking, maximum, OR)-(Figure 4).

This has resulted in kind of decision maps that support the decision makers and planners. Each decision map has categorized into equal interval-five classes based on the aggregated scale $(0-255)$. These four scenarios are:

1) The first scenario is based on applying the minimum risk throughout the risk-averse (AND) model where there is no tradeoff and minimum risk. It considers the minimum weights of the driving factors generating the hazards. Figure 5 shows the decision map of this scenario where the aggregated hazard values are distributed from 22 to 241 . This shows that the majority of the area of study in this scenario is dominated by class3 (i.e. moderate hazards). This is actually representing nearly $90 \%$ of the study area, Figure 9 and Table 2.

2) The second scenario is the maximum risk is applied in the risk-taking (OR) model. It considers the maximum weights of the driving factors contribute to the hazards. Figure 6 shows the decision map resulted from this scenario. It shows that the aggregated hazard weights are distributed from 173 to 255 . This scenario shows that the majority of the study area is dominated by class 5 (extremely hazards). This means that $99 \%$ of the study area is under high risk of hazards from this scenario (Figure 9, Table 2).

3) The third scenario is the alternatives between low risk and high tradeoff where low risk-high trade off (MIDAND) model is applied. It considers the median order weights of the no-and-full trade off and the risk-averse (AND) values of the factors affecting the hazards. Figure 7 shows the decision map resulted from this scenario, where the hazard weights are scaled from 26 to 250. This scenario has categorized the study area into various hazards categories. Nearly $50 \%$ of the study area is in class 4 (high hazards), nearly $20 \%$ is located in class 3 (moderate hazards), while about $15 \%$ is located in class 2 (low hazards), and 13\% in class 1 (very low hazards), Figure 9 and Table 2. This means that more stable areas of classes 1 and 2 are shown in this scenario. 
4) The fourth scenario is the alternatives between high risk and low tradeoff where high risk-low trade off (MIDOR). It considers the median order weights of the no-and-full trade off and the risk-taking (OR) values of the driving factors contributing to the hazards. Figure 8 shows the outcomes of this scenario, the decision map shows a scaled hazard weight values from 133 to 255. This scenario has also categorized the area of study into different hazards zones. The area of study is fully hazards area, the majority (75\%) is considered extreme hazard (class 5 ), however only $25 \%$ is high risk (class 4 ) Figure 9 and Table 2. This means that the more stable areas of classes 1 and 2 are totally disappeared in this scenario while the more hazardous classes are dominated.

\section{Conclusions}

Six driving factors contribute to the hazards at MPA have been analyzed and modelled and showed different degrees of contribution to the risk and hazard. Lithology and geological structures factors (faults, joints) are sharing in hazards potentiality by about $65 \%$ reference to their eigenvector of weights. The geomorphic processes (slope gradient and old wadies/surface drainage) are about $30 \%$ potentiality to hazard especially at the high and sharp cliffs of the MPA. Although, the model shows that quarrying activities, as one of the human activities, are contributed by only 5\%; the other human impact of urbanization is an active driver which is not considered in the model, which accelerates the natural geology, structure and geomorphic processes drivers for landslide and rock-falls potentialities.

The application of the MCE AHP-OWA model shows potential of generating different options with multiple scenarios that could be flexible for decision makers and planners. This, indeed, will ease the process to select which areas are the

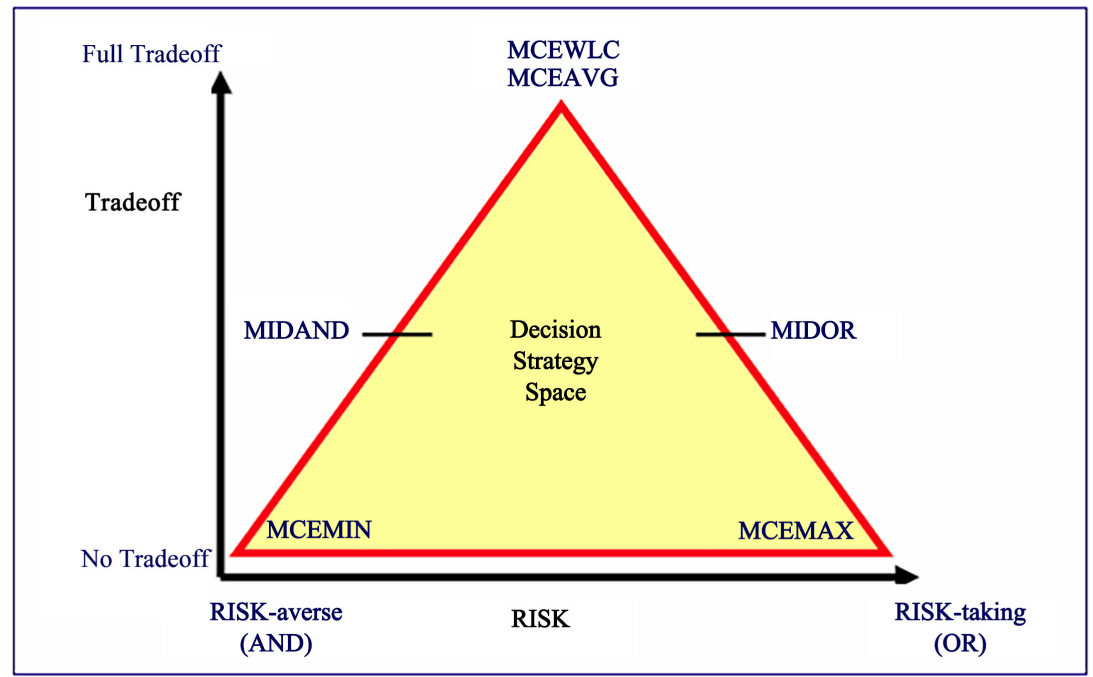

Figure 4. The MCE AHP-OWA options through risk and tradeoff along the decision strategy space (source: IDRISI Andes manual). 


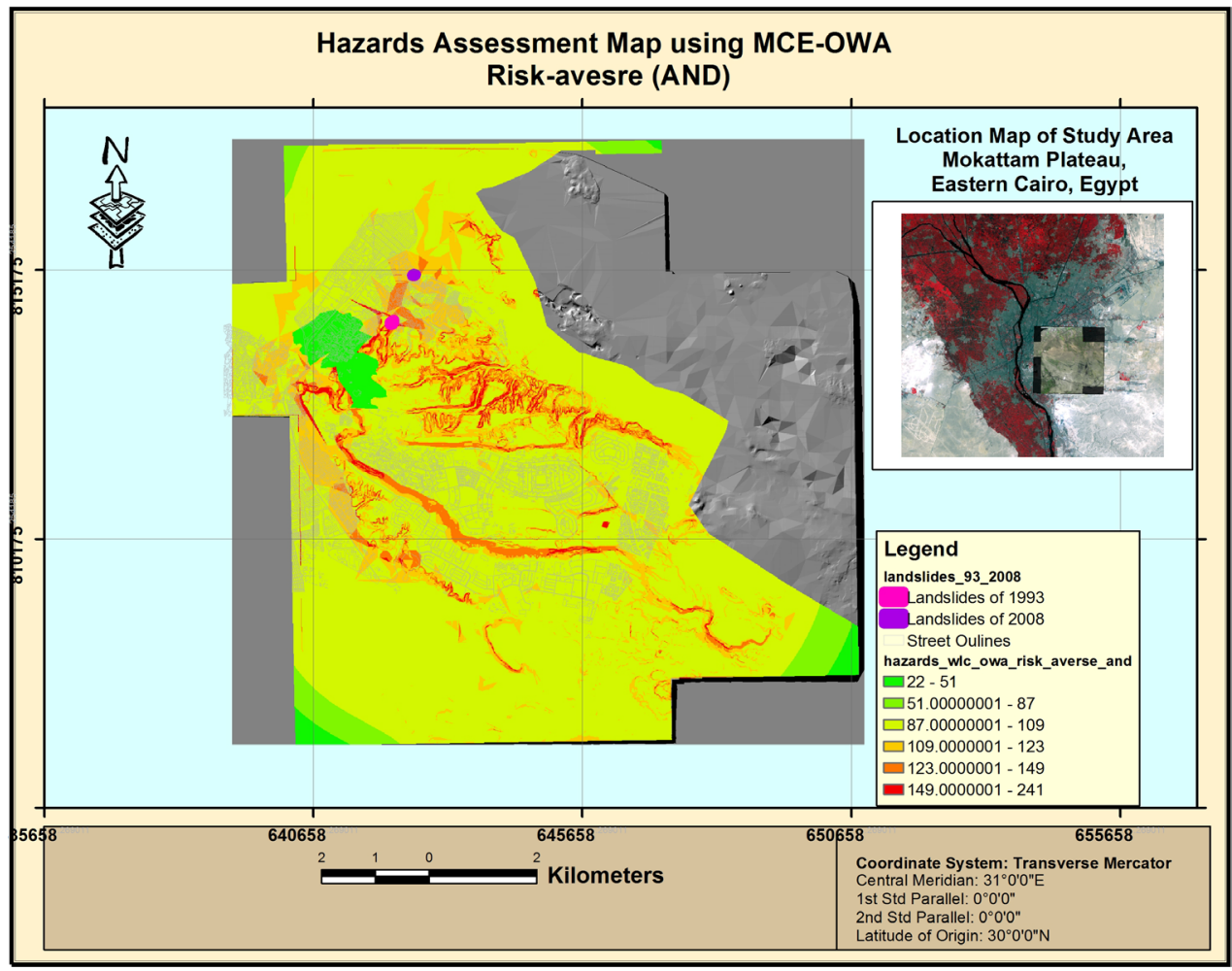

Figure 5. Outcomes of scenario 1-hazards assessment decision map using AHP-OWA Riskaverse (AND) model.

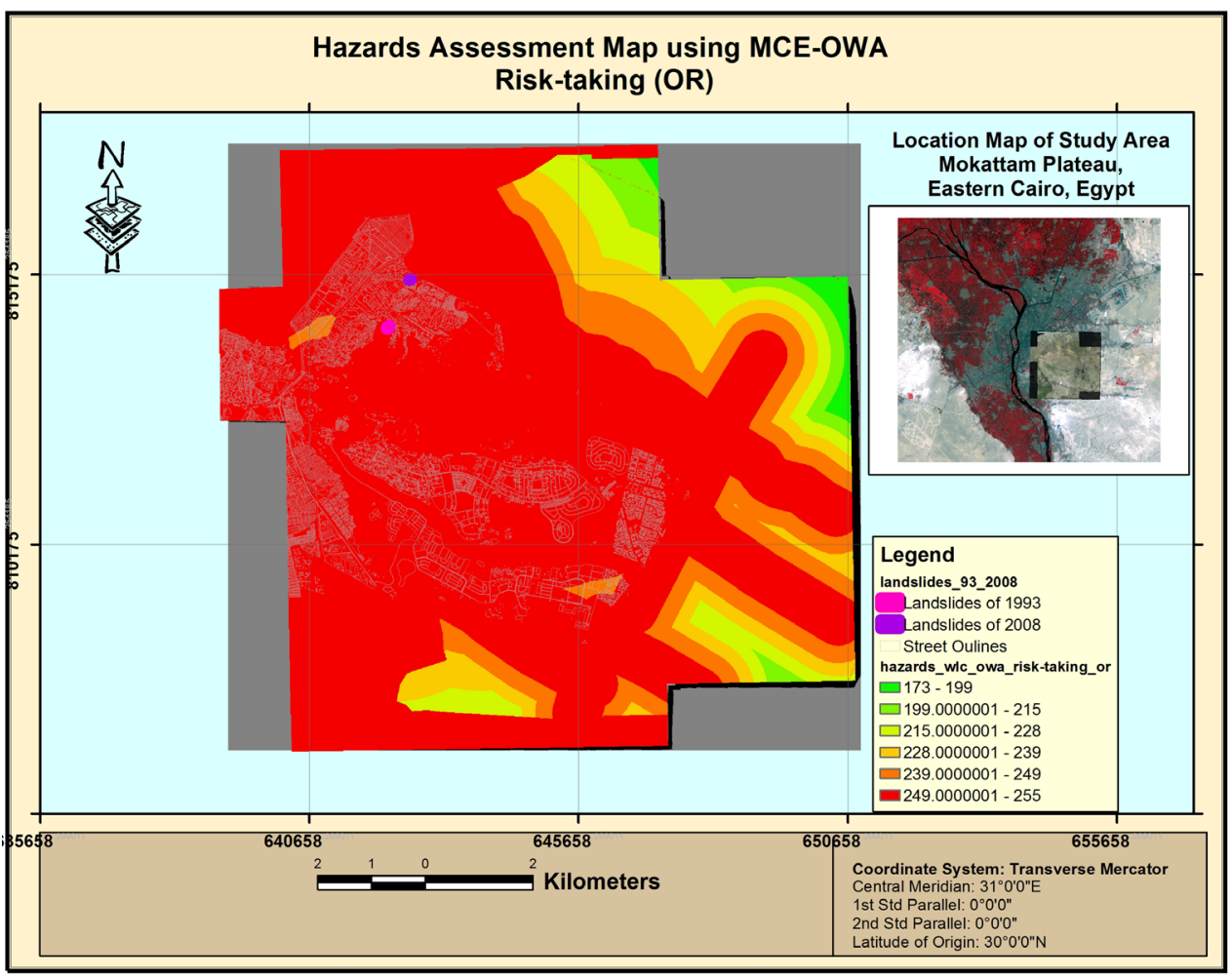

Figure 6. Outcomes of scenario 2-hazards assessment decision map using AHP-OWA Risk-taking (OR) model. 


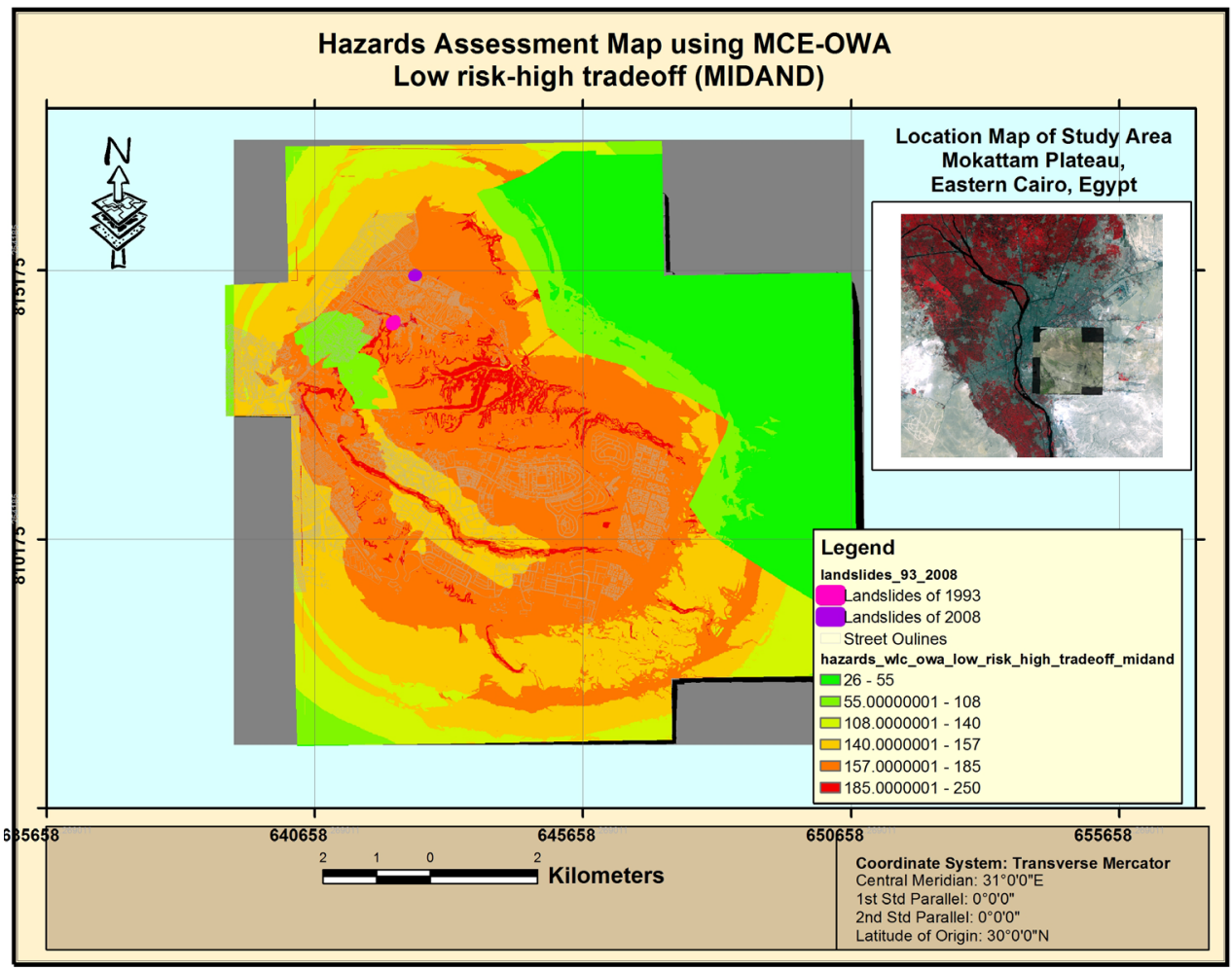

Figure 7. Outcomes of scenario 3-hazards assessment decision map using AHP-OWA low risk-high tradeoff (MIDAND) model.

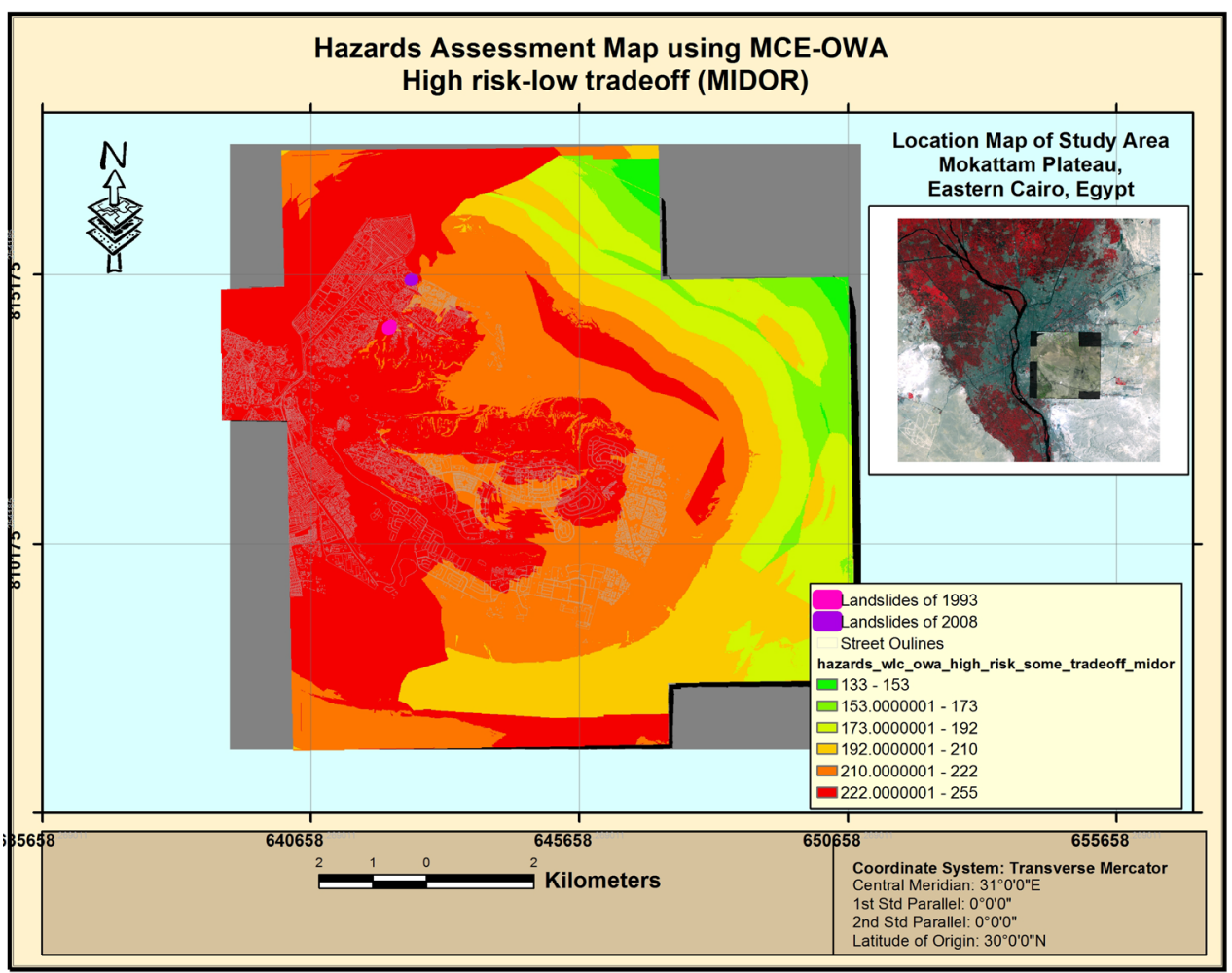

Figure 8. Outcomes of scenario 4-hazards assessment decision map using AHP-OWA high risk-low tradeoff (MIDOR) model. 


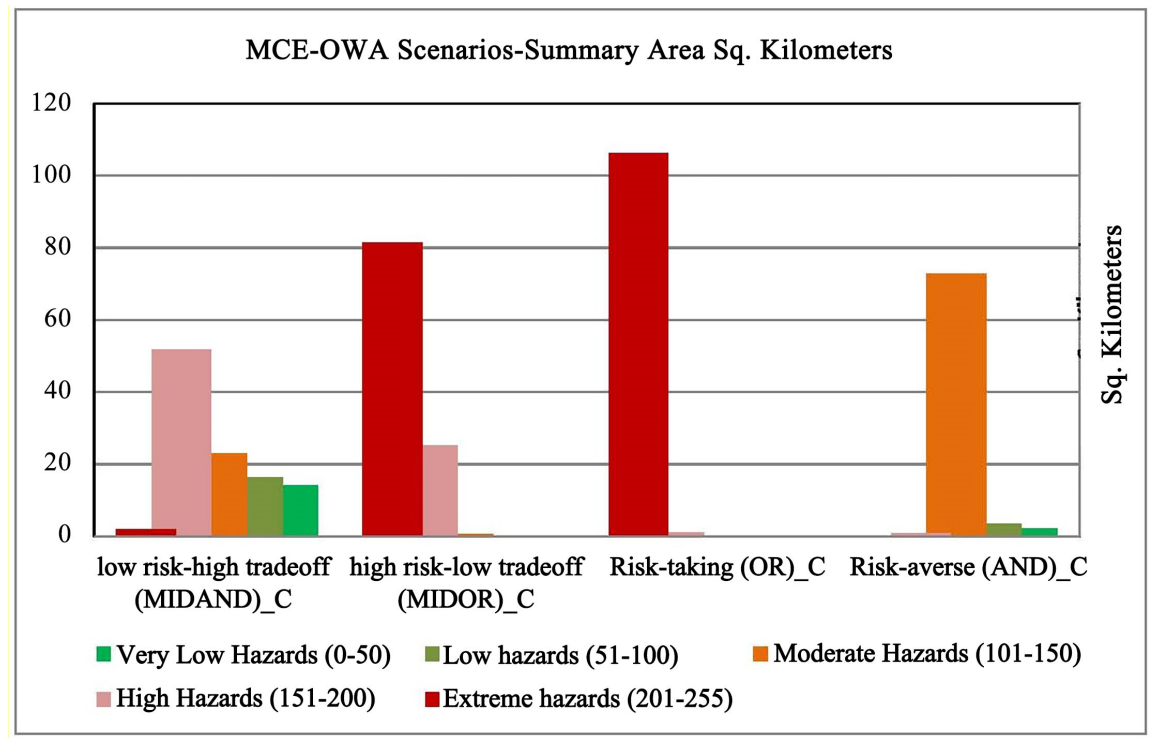

Figure 9. Summary areas of the MCE-AHP-OWA scenarios.

Table 2. Percentages of the summary areas of the MCE AHP-OWA scenarios.

\begin{tabular}{|c|c|c|c|c|}
\hline \multirow[b]{2}{*}{ Class of Hazards } & \multicolumn{4}{|c|}{ Areas (Sq. Km) of the MCE AHP-OWA Scenarios } \\
\hline & $\begin{array}{l}\text { Risk-averse } \\
\text { (AND) }\end{array}$ & $\begin{array}{l}\text { Risk-taking } \\
\quad(\mathrm{OR})\end{array}$ & $\begin{array}{l}\text { High risk-low } \\
\text { trade off (MIDOR) }\end{array}$ & $\begin{array}{c}\text { Low risk-high } \\
\text { trade off (MIDAND) }\end{array}$ \\
\hline $\begin{array}{c}\text { Class } 1(0-50) \text {-very } \\
\text { low hazards }\end{array}$ & 2.80 & 0.00 & 0.00 & 13.13 \\
\hline $\begin{array}{c}\text { Class } 2(51-100)-\text { low } \\
\text { hazards }\end{array}$ & 4.43 & 0.00 & 0.00 & 15.31 \\
\hline $\begin{array}{c}\text { Class } 3(101-150)- \\
\text { moderate hazards }\end{array}$ & 91.58 & 0.00 & 0.63 & 21.48 \\
\hline $\begin{array}{c}\text { Class } 4(151-200)- \\
\text { high hazards }\end{array}$ & 1.16 & 0.95 & 23.52 & 48.21 \\
\hline $\begin{array}{l}\text { Class } 5(201-255)- \\
\text { extreme hazards }\end{array}$ & 0.04 & 99.05 & 75.85 & 1.86 \\
\hline
\end{tabular}

suitable for sustainable development especially for urban development with low risk. It will be interactively enable to select the appropriate scenario to apply that meets the planners' guidelines and civil codes. The MCE model provided an option of the safest scenario to be used for land allocation for new urban development projects is the risk-taking (OR) scenario to avoid any risk and be resilience. This is followed by the high risk-low tradeoff (MIDOR) scenario with some conditions to be considered. The limitations and conditions will be increased when using the low risk-high tradeoff (MIDAND) scenario, and even further constrains for the risk-averse (AND) scenario, which are minimizing the contribution of the risk factors in the MCE-OWA model. Figure 10 shows the distribution of the urbanization within the MPA along the analyzed four MCE AHP-OWA scenarios. 


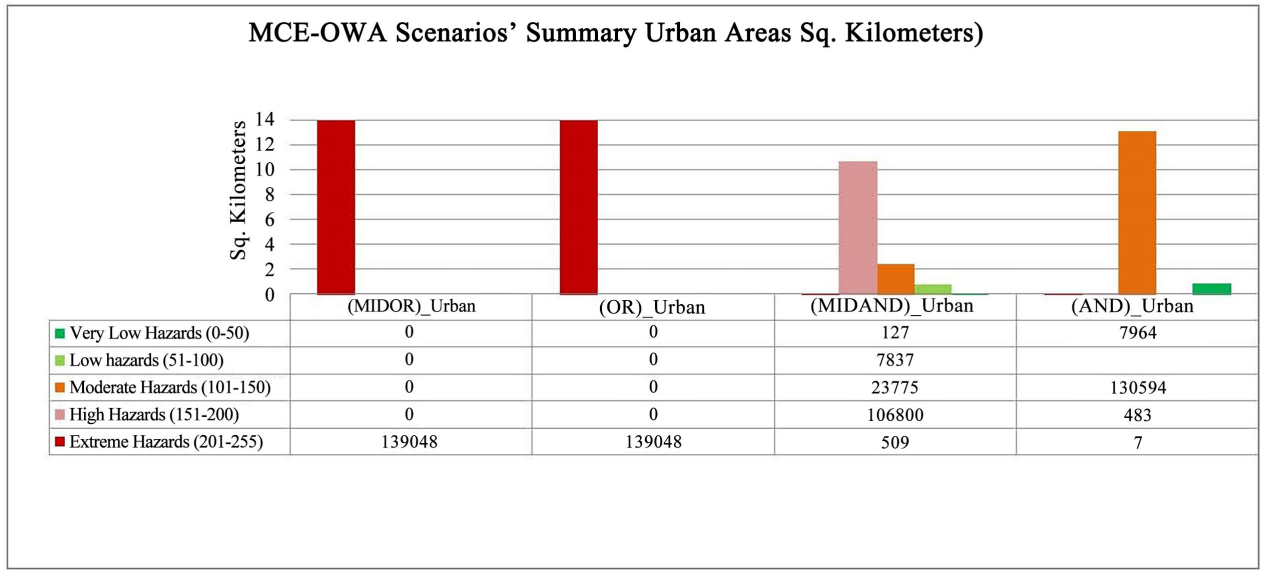

Figure 10. Summary of the urban areas of the MCE-AHP-OWA scenarios.

According to the Sendai framework for disaster risk reduction 2015-2030 (UNISDR, 2015): "Prevent new and reduce existing disaster risk through the implementation of integrated and inclusive economic, structural, legal, social, health, cultural, educational, environmental, technological, political and institutional measures that prevent and reduce hazard exposure and vulnerability to disaster, increase preparedness for response and recovery, and thus strengthen resilience". Therefore, the decision-makers should be taken into consideration the factors accelerating the hazards and act to mitigate the risks by applying the disaster risk management plans at the most vulnerable areas.

By applying this methodology to evaluate an existing built up area, it is not easy to decide which scenario to apply. When I made a mask of urban area polygons on the output maps of the four scenarios, I found that almost $100 \%$ of the urbanization is located in the class 5 in the scenarios risk-taking (OR) and high risk-low trade off (MIDOR). While about $75 \%$ of the urbanization is located in class 4 in the scenario (MIDAND) and about $93 \%$ in class 3 in the scenario (AND), Figure 9. Therefore, the decision here is very difficult to maintain the risky situation of such urban areas.

Finally, it is recommended to apply the MCE (AHP-OWA-WLC) methodology, for its integrated and comprehensive perspective, to achieve more resilient and sustainable development of the new urban development projects. The most suitable scenario to evaluate these projects is the risk-taking (OR) then the high risk-low trade off (MIDOR) models. But for stability evaluation of our study area (MPA), the decision makers need to interactively use this model with updated information to ensure optimum accuracy and safer scenario.

\section{Acknowledgements}

I would like to thank Dr. Islam Abou El-Magd, Professor at National Authority for Remote Sensing and Space Sciences (NARSS)-Egypt, for his valuable revision of the manuscript. In addition, I would like to pay thanks for my esteemed institution, the Arab Academy for Science, Technology and Maritime Transport 
(AASTMT) for encouragement.

\section{Conflicts of Interest}

The author declares no conflicts of interest regarding the publication of this paper.

\section{References}

Albrecht, J. H. (1996). Universal GIS Operations for Environmental Modeling. Proceedings of the 3rd International Conference/Workshop on Integrating Geographic Information Systems and Environmental Modeling, Santa Fe, NM, 21-25 January 1996, National Center for Geographic Information and Analysis (NCGIA).

Amasha, A. (2009). Application of Remote Sensing, GIS and Multi-Criteria Evaluation in Hazard Assessment for Sustainable Development of GabalMokattam Area, East Cairo, Egypt (p. 167). Ph.D. Thesis, Egypt: Geology Department, Faculty of Science, Mansoura University.

CAPMAS (2017). The Estimated Census Data of Jan. 2017. http://www.capmas.gov.eg/Pages/StaticPages.aspx?page_id=5034

Carrara, A., Cardinali, M., Detti, R., Guzzettt, F., Pasqui, V., \& Reichenbach, P. (1991). GIS Techniques and Statistical Models in Evaluating Landslide Hazard. Earth Surface Processes and Landforms, 16, 427-445.

Carver, S. (1991). Integrating Multi-Criteria Evaluation with Geographical Information Systems. International Journal Geographical Information Systems, 5, 321-339.

Eastman, J. R. (2006). IDRISI Andes Manual, Guide to GIS and Image Processing. Clark Labs, Clark Uni. https://clarklabs.org/

Eastman, J. R., \& Jiang, H. (1996). Fuzzy Measures in Multi-Criteria Evaluation. 2nd International Symposium on Spatial Accuracy Assessment in Natural Resources and Environmental Studies, Fort Collins, 21-23 May 1996, 527-534.

Gunawan, I., Giardino, J. R., \& Tchakerian, V. P. (1992). Displaying and Evaluating Engineering Properties and Natural Hazards Using Geomorphic Mapping Techniques. Geological Society America Abstracts with Programs, 24, 18.

Lee, S., \& Pradhan, B. (2006). Probabilistic Landslide Risk Mapping at Penang Island, Malaysia. Journal of Earth System Science, 115, 661-672. https://doi.org/10.1007/s12040-006-0004-0

Lee, S., \& Pradhan, B. (2007). Landslide Hazard Mapping at Selangor, Malaysia Using Frequency Ratio and Logistic Regression Models. Landslides, 4, 33-41. https://doi.org/10.1007/s10346-006-0047-y

Moustafa, A. R., El-Nahhas, F., \& Abdel Tawab, S. (1991). Engineering Geology of Mokattam City and Vicinity, Eastern Greater Cairo, Egypt. Engineering Geology, 31, 327-344. https://doi.org/10.1016/0013-7952(1)90015-D

National Authority for Remote Sensing and Space Sciences (NARSS) and Egyptian Geological Survey and Mining Authority, (EGSMA). Several Geological, Geomorphological and Geotechnical Studies for Selected Areas of Mokattam Plateau, as Internal Reports, in Years from 1993 to 2002.

Pradhan, B., \& Lee, S. (2007). Utilization of Optical Remote Sensing Data and GIS Tools for Regional Landslide Hazard Analysis by Using an Artificial Neural Network Model at Selangor, Malaysia. Earth Science Frontier, 14, 143-152.

https://doi.org/10.1016/S1872-5791(08)60008-1 
Pradhan, B., \& Lee, S. (2009a). Landslide Susceptibility Assessment and Factor Effect analysis: Back Propagation Artificial Neural Networks and Their Comparison with Frequency Ratio and Bivariate Logistic Regression Modeling. Environmental Modelling \& Software, 25, 747-759. https://doi.org/10.1016/j.envsoft.2009.10.016

Pradhan, B., \& Lee, S. (2009b). Landslide Risk Analysis Using Artificial Neural Network Model Focusing on Different Training Sites. International Journal of Physical Sciences, 3, 1-9.

Pradhan, B., Lee, S., \& Buchroithner, M. F. (2009). Use of Geospatial Data for the Development of Fuzzy Algebraic Operators to Landslide Hazard Mapping: A Case Study in Malaysia. Applied Geomatics, 1, 3-15.

Ritter, D. F. (1988). Landscape Analysis and the Search for Geomorphic Unity. Geological Society of America Bulletin, 100, 160-171. https://doi.org/10.1130/0016-7606(1988)100<0160:LAATSF>2.3.CO;2

Ritter, D. F., Kochel, R. C., \& Miller, J. R. (2001). Process Geomorphology (4th ed., p. 560). New York: McGraw-Hill College.

Roy, B. (1996). Multicriteria Methodology for Decision Aiding. Dordrecht: Kluwer Academic Publishers. https://doi.org/10.1007/978-1-4757-2500-1

Saaty, T. L. (1977). A Scaling Method for Priorities in Hierarchical Structures. Journal of Mathematical Psychology, 15, 234-281. https://doi.org/10.1016/0022-2496(77)90033-5

Saaty, T. L. (1980). The Analytic Hierarchy Process, Planning, Priority Setting, Resource Allocation (p. 287). New York: McGraw-Hill.

Saaty, T. L. (1996). Decision Making for Leaders: The Analytical Hierarchy Process for Decisions in a Complex World. Vol. II. The Analytic Hierarchy Process Series (3rd ed., p. 291). Pittsburgh: RWS.

Saaty, T. L. (2003). Decision Making with the AHP. Why Is the Principle Eigenvector Necessary. European Journal of Operational Research, 145, 85-91. https://doi.org/10.1016/S0377-2217(02)00227-8

Schumm, S. A. (1973). Geomorphic Thresholds and Compels Response in Drainage Systems. Fluvial Geomorphology, Binghamton, 299-310.

UNISDR (2015). Sendai Framework for Disaster Risk Reduction 2015-2030 (p. 32). United Nations Office for Disaster Risk Reduction (UNISDR). https://www.unisdr.org/we/inform/publications/43291

Voogd, H. (1983). Multicriteria Evaluation for Urban and Regional Planning. London: Pion Ltd.

Yager, R. (1988). On Ordered Weighted Averaging Aggregation Operators in Multi-Criteria Decision Making. IEEE Transactions on Systems, Man, and Cybernetics, 18, 183-190. https://doi.org/10.1109/21.87068 